\title{
Printed anesthetic-risk information and perioperative anxiety: a multi-center study
}

\author{
Suwannee Suraseranivongse ${ }^{\mathrm{a}}$, Busakorn Wungpayon ${ }^{\mathrm{b}}$, Phuping Akavipat ${ }^{\mathrm{c}}$, Paron Prownpun ${ }^{\mathrm{d}}$, \\ Sireeluck Klanarong ${ }^{\mathrm{d}}$ \\ ${ }^{a}$ Department of Anesthesiology, Faculty of Medicine Siriraj Hospital, Mahidol University, Bangkok \\ 10700; 'Department of Anesthesia, Pichit Hospital, Pichit 66000; 'Department of Anesthesia, Prasart \\ Neurological Institute, Bangkok 10400; 'Department of Anesthesia, Buddhachinaraj Hospital, \\ Phitsanulok 65000, Thailand
}

\begin{abstract}
Background: Currently, there is a considerable variation concerning the provision of preanesthetic-risk information, especially potential detrimental adverse outcomes.

Objective: Determine the effects of printed anesthetic-risk information before surgery including patients' anxiety, refusal of surgery, knowledge perception of adverse events and factors affecting anxiety.

Methods: Patients in a university hospital, a tertiary care hospital, a secondary care hospital, and a neurological institute in Thailand, undergoing low-to-moderate risk surgery were randomly allocated to control group (C) and study group (S), where group C received printed general information in anesthesia, and group $S$ received printed incidences of five anesthetic adverse events as sore throat, nausea/vomiting, tooth loss, not waking up after surgery, cardiac arrest. Spielberger State-Trait Anxiety Inventory Scale (STAIS, STAIT) for anxiety and Visual Analog Scale (VAS) for knowledge perception were recorded before and after information, and after surgery. Numbers of patients who refused surgery and needed anesthetic-risk information in the next surgery were also recorded. STAIS $>45$ were considered "high anxiety".

Results: Eight-hundred and twenty-four patients were analyzed (group C: 414, group S: 410). There was no difference in age, sex, ASA physical status, salary, education level, habitat, anesthetic experience and operative risk between groups. STAIS and STAIT, proportion of patients with high anxiety, proportion of patients who refused surgery were not different between groups. Patients in control group needed anesthetic-risk information in the next surgery more than study group ( $\mathrm{p}<0.001)$. VAS for knowledge about five adverse events in study group were significantly higher than control group $(\mathrm{p}<0.001)$. Risk factors by the multivariate analysis included patients with high baseline trait anxiety and low income of less than 10,000 Baht/month.

Conclusion: Printed anesthetic-risk information did not increase anxiety, but increased knowledge perception of the patients.
\end{abstract}

Keywords: Anesthetic risk, anxiety, information, knowledge

It is a standard practice to provide anestheticrisk information to patients for their appropriate decision-making [1-4]. The disclosed potential risks include common and rare outcomes [5], but there is a

This article was presented at the $13^{\text {th }}$ Asian Australasian Congress of Anesthesiologists (Fukuoka, Japan in June, 2010). Correspondence to: Suwannee Suraseranivongse, MD, Department of Anesthesiology, Faculty of Medicine Siriraj Hospital, Mahidol University, Bangkok 10700, Thailand. E-mail: sisur@mahidol.ac.th considerable variation concerning the detail and nature of the disclosed information. In Thailand, anesthetic information before surgery consists of presentation of alternatives and their benefits, but the explicit discussion about potential detrimental adverse outcomes is usually avoided to prevent aggravating the patient fear and anxiety, which may lead to cancellation of surgery.

According to the Association of Anaesthetists of Great Britain and Ireland, information about rare but 
serious complications should be provided in written information [6]. The effects of pre-operative statistical anesthetic-risk information were investigated in the patients who had experience with previous anesthesia. Those who received more detailed information about incidence of severe adverse events gained more knowledge. But the state of anxiety in these patients was not different from the patients who received merely routine pre-operative information [7].

In Thailand, the low litigation rates in the past are undergoing change. Anesthetic-risk information seems to be more necessary. Previously, we developed printed anesthetic-risk information, gathering incidents of adverse events from Thai study [8] and from other countries [9], including a community cluster logarithmic scale of risk [9-11]. In this study, we determined the effects of this preprint anesthetic-risk information on preoperative anxiety and knowledge of adverse events for patients from different settings. A multi-center study was conducted in multi-level hospitals, both in rural and urban areas where patients' characteristics and care might not be similar. In addition, factors influencing patients' anxiety on receiving this information were also identified.

\section{Methods}

This prospective randomized controlled trial was approved by the Institutional Ethics Committee at Siriraj Hospital (a university hospital at Bangkok), Budhachinaraj Hospital (a tertiary care hospital in a rural area), Pichit Hospital (a secondary care hospital in a rural area), and Prasart Neurological Institute (a specific tertiary care hospital at Bangkok). (This study was registered with the Clinical Trials Registry, No. 0081669.)

After obtaining informed consent, patients undergoing low-to-moderate risk surgery under general anesthesia, with or without regional block, were enrolled. Literate patients, ages ranged from 16 to 80 years old were included. This study excluded patients who were undergoing intracranial surgery and cardiothoracic surgery, those who had post-operative alteration of consciousness, emergency patients and those with neurological or psychiatric diseases.

Patients were stratified based on age $(\leq 50$ or $>50$ years) [7], sex (male or female) [12] and risk of surgery (low risk and moderate risk according to the Guideline of American Heart Association) [13]. Then, patients in each stratum were randomly allocated into a control group and a study group by using random number table, block of four randomization and concealed envelope technique.

Anxiety and knowledge perception about five anesthetic adverse events (sore throat, nausea and vomiting, dental damage, not waking up after surgery and cardiac arrest) were measured in all patients, i) before receiving information, ii) after receiving information, and iii) after surgery when the patients were alert and capable of being interviewed. Patients in the study group received information printed about anesthetic-risk incidence of general anesthesia [8, 9] and regional anesthesia $[8,9]$ including a community cluster logarithmic scale of risk (modified from Charuluxananan [8], Jenkins and Barker [9], Calman and Roy stone [10], and Adams and Smith [11]). Patients in the control group received only information printed about general preparation for anesthesia. The leaflets in both groups were printed in the similar size and color.

Data collection included i) demographic data (data, sex, address, ASA physical status, education, family income, anesthetic experience), ii) type of surgery, iii) anesthetic techniques, iv) anxiety level, and v) knowledge perception level.

Anxiety level was measured by using Spielberger State Trait Anxiety Inventory Scale (STAI). The STAI consisted of two evaluation forms to assess state anxiety level (STAIS) or anxiety related to acute situation and trait anxiety level (STAIT) or anxiety related to personality feature. Each form of STAIS and STAIT consisted of 20 statements. Then, each statement was rated on a four-point scale. The overall score for STAI ranges from a minimum of 20 to a maximum of 80 . A mean STAI anxiety score of 35 is considered normative for adults in the different age group [14]. The literature suggests defining the highanxiety state at one standard deviation (SD) above the normative mean, i.e. STAI $>45$ [15]. Therefore, a STAT score of 45 is used as the reference point. Patients would either fill the form by themselves or research nurses would fill in the form according to patients' directions.

Perception of knowledge about anesthetic adverse events both common, but not serious (sore throat, nausea and vomiting, dental damage) and rare but serious (not waking up after surgery and cardiac arrest), were measured by patients' self assessment using Visual Analogue Scale (VAS).

After operation, numbers of patients who refused surgery, refused regional anesthesia in case of 
combined general and regional anesthesia, and refused any anesthetic-risk information before the next operation were recorded

Sample size was estimated based on comparison of proportion of high anxiety (score $>45$ ) between patients receiving routine information (control group) and printed anesthetic-risk information (study group). A previous study reported that mean (SD) score of anxiety in the control group was 35.2 (SD: 12.3) [7]. If anxiety score was assumed to distribute normally, approximately $68 \%$ of patients would have score between 23 and 47 . Thus, roughly $17 \%$ would have a score of greater than 45 . Then, we assumed that $20 \%$ of patients in the control group would have score $>45$, compared to $30 \%$ in the study group. Using a twosided type I error of $0.05,90 \%$ power, a sample of 392 per group would be adequate to test the difference in two proportions of $20 \%$ vs. $30 \%$. With the anticipated drop-out rate of $10 \%, 872$ patients were then required.

\section{Statistical analysis}

Demographic data were analyzed using descriptive statistics. Parametric variables were compared using unpaired t-test. Non-parametric variables were compared using Mann Whitney U test. Categorical variables were analyzed using Chi square (or Fisher exact) test.

Risk factors of high anxiety level were analyzed by defining dependent factors as high STAIS after receiving information and using a cut-off point of 45 [15]. Independent factors included age ( $\leq 50$ or $>50$ years old), sex (male or female), baseline trait anxiety ( $\leq 45$ or $>45$ ), patients' habitat (urban or rural) ASA physical states (I-II or III-V), education level ( $\leq$ high school or $>$ high school), family income monthly ( $\leq 10,000$ or $>10,000$ baht), anesthetic experience (yes or no), operative risk (mild or moderate), anesthetic technique (general or combined general + regional anesthesia), location of hospital (urban or rural). Chisquare or Fisher Exact test was used for univariate analysis and multiple logistic regression analysis was used for multivariate analysis. A p-value of less than 0.05 was considered to be of statistical significance.

\section{Results}

Eight hundred and seventy-four patients were enrolled. All patients were treated by intention-to-treat basis. Fifty patients dropped out due to surgeons' cancellation (seven cases), arrhythmia before surgery (five cases), changing from general anesthesia to local anesthesia by surgeon's request (one case) and changing to spinal anesthesia by anesthetists' request (six cases), patients' discharge earlier than research nurses' visit (12 cases), postoperative coma (one case) and delirium (one case), ventilatory support after surgery (two cases), death after surgery (three cases) and incomplete STAI scale (12 cases). Finally, 414 patients in the control group and 410 patients in the study group remained for analysis (Figure 1).

Table 1 shows characteristics, anesthetic techniques and operative risk in the control and study group. We note that patients' characteristics, baseline trait anxiety, risk of surgery and anesthetic risk were not different between control group and study group.

Table 2 shows state anxiety score, trait anxiety score, proportion of patients with high anxiety in the control and study group. We note that STAIS and STAIT before and after receiving information (including after surgery) were not different between the two groups. High state anxiety scores after receiving both routine and anesthetic-risk information were found in $23.7 \%$ of patients. The proportion of patients with high STAIS after receiving information and the proportion of patients who refused surgery or regional anesthesia were not different. After surgery, patients in the control group would prefer to have further anesthetic-risk information before their next surgery more often than in study group.

Table 3 shows visual analogue score of knowledge perception in control and study group. We note that the visual analogue scores of five adverse events before receiving information between groups were not different. After receiving information, those scores were significantly higher in the study group than in the control group.

Table 4 shows various factors affecting high state anxiety $>45$ after information by univariate analysis. We note that factors influencing higher state anxiety after receiving information included patients in university hospitals, being in the younger age group (up to 50 years), higher baseline trait anxiety, being subject to combined anesthetic technique, and lower income.

Table 5 shows factors affecting high state anxiety (STAIS) $>45$, after information, by multiple logistic regression analysis. Interestingly, risk factors from multiple logistic regression analysis determined that only high baseline trait anxiety and lower income were relevant. 


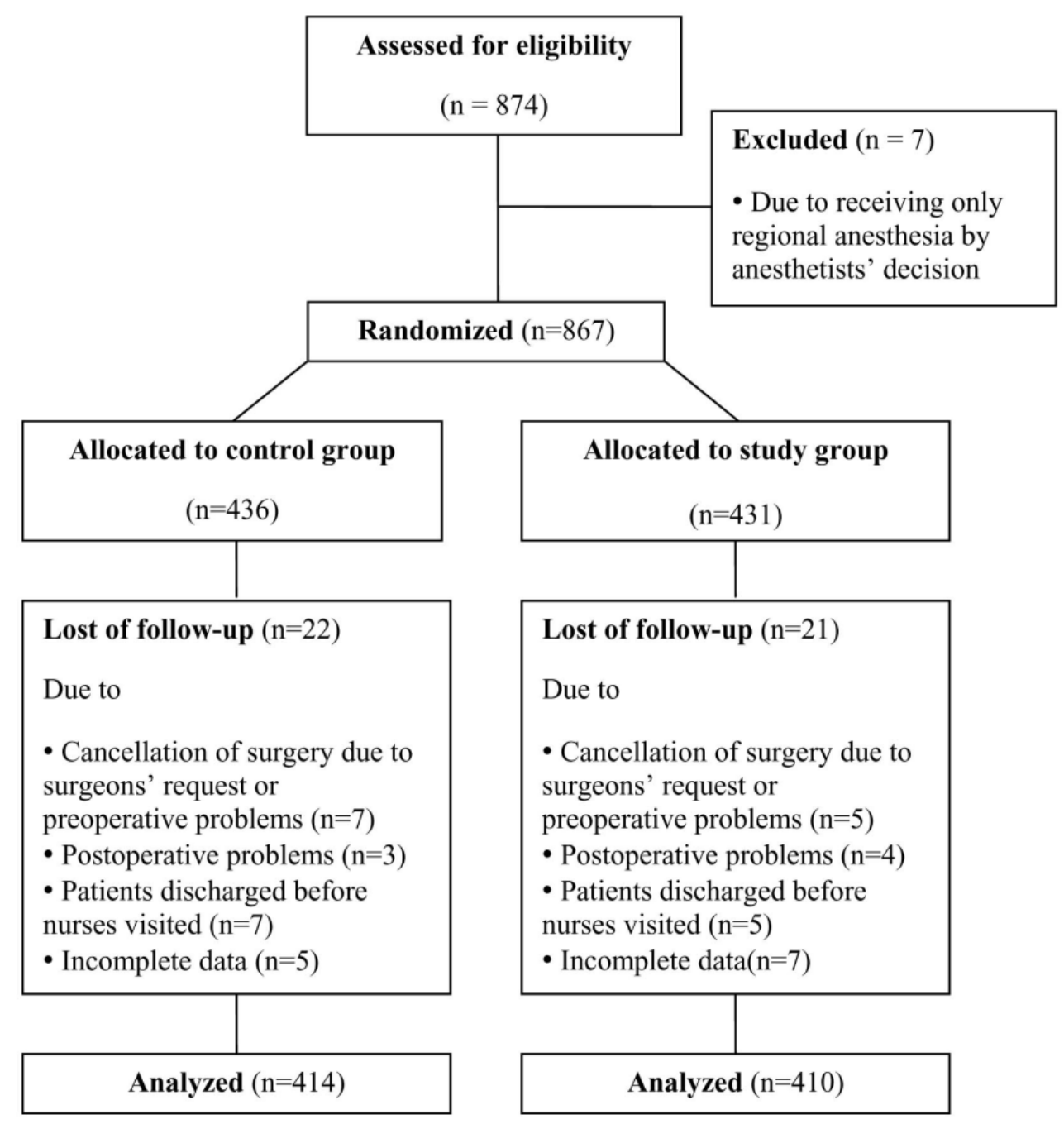

Figure 1. Consort diagram for study.

Table 1. Characteristics, anesthetic techniques and operative risk in patients who received routine anesthetic information (control group) and anesthetic-risk information (study group). Values are expressed as mean (SD) or number (proportion).

\begin{tabular}{|c|c|c|c|}
\hline & $\begin{array}{c}\text { Control group } \\
\quad(n=414)\end{array}$ & $\begin{array}{l}\text { Study group } \\
\quad(n=410)\end{array}$ & P-value \\
\hline Age (years) & 49.16(13.58) & 49.33(13.04) & $0.857^{*}$ \\
\hline Sex (male: female) & $187: 227$ & $165: 245$ & $0.153^{* *}$ \\
\hline \multicolumn{4}{|l|}{ STAIT baseline } \\
\hline$>45$ & $72(17.4 \%)$ & $64(15.6 \%)$ & \multirow[t]{2}{*}{$0.491^{* *}$} \\
\hline$<45$ & $342(82.6 \%)$ & $346(84.4 \%)$ & \\
\hline \multicolumn{4}{|l|}{ ASA physical status } \\
\hline I, II & $389(94.4 \%)$ & $388(94.6 \%)$ & \multirow[t]{3}{*}{$0.891^{* *}$} \\
\hline III-V & $23(5.6 \%)$ & $22(5.4 \%)$ & \\
\hline Missing & 2 & & \\
\hline \multicolumn{4}{|l|}{ Salary } \\
\hline$<10,000$ baht/month & $216(75.5 \%)$ & $220(75.3 \%)$ & \multirow[t]{4}{*}{$0.610^{* *}$} \\
\hline 10,001-20,000 baht/month & $38(13.3 \%)$ & $45(15.4 \%)$ & \\
\hline$>20,000$ baht/month & $32(11.2 \%)$ & $27(9.2 \%)$ & \\
\hline Missing & 128 & 118 & \\
\hline
\end{tabular}


Table 1. Characteristics, anesthetic techniques and operative risk in patients who received routine anesthetic information (control group) and anesthetic-risk information (study group). Values are expressed as mean (SD) or number (proportion). (Continued)

\begin{tabular}{|c|c|c|c|}
\hline & $\begin{array}{c}\text { Control group } \\
(n=414)\end{array}$ & $\begin{array}{l}\text { Study group } \\
\quad(n=410)\end{array}$ & P-value \\
\hline \multicolumn{4}{|l|}{ Education } \\
\hline$\leq$ High school & $337(81.6 \%)$ & $331(80.7 \%)$ & $0.826^{* *}$ \\
\hline$>$ High school & $76(18.4 \%)$ & $72(19.3 \%)$ & \\
\hline Missing & 1 & 7 & \\
\hline \multicolumn{4}{|l|}{ Anesthetic technique } \\
\hline General anesthesia & $399(96.4 \%)$ & $395(96.3 \%)$ & $0.978^{* *}$ \\
\hline $\begin{array}{l}\text { General + Regional } \\
\text { anesthesia }\end{array}$ & $15(3.6 \%)$ & $15(3.7 \%)$ & \\
\hline \multicolumn{4}{|l|}{ Anesthetic experience } \\
\hline No & $213(51.6 \%)$ & $193(47.5 \%)$ & $0.221 * *$ \\
\hline Yes & $200(48.4 \%)$ & $215(52.7 \%)$ & \\
\hline Missing & 1 & 2 & \\
\hline \multicolumn{4}{|l|}{ Operation (number, \%) } \\
\hline Low risk & $151(36.5 \%)$ & 148(36.1\%) & $0.890 * *$ \\
\hline Moderate risk & $263(63.5 \%)$ & $262(63.9 \%)$ & \\
\hline
\end{tabular}

* Unpaired t-test, **Chi square or Fisher exact test.

Table 2. State anxiety score (STAIS), Trait anxiety score (STAIT), proportion of patients with high anxiety, patients who refused surgery and needed information in control group who received routine anesthetic information and study group who received anesthetic-risk information. Values are expressed as median (IQR), number (proportion).

\begin{tabular}{|c|c|c|c|}
\hline & Median (I & ber (\%) & \\
\hline & $\begin{array}{l}\text { Control group } \\
(n=414)\end{array}$ & $\begin{array}{l}\text { Study group } \\
(n=410)\end{array}$ & P-value \\
\hline STAIS & & & \\
\hline Before information & & & \\
\hline - Score & $41(36,46)$ & $41(36,46.25)$ & 0.461 \\
\hline - Patients with high anxiety & $72(17.4 \%)$ & $64(15.6 \%)$ & 0.491 \\
\hline After information & & & \\
\hline - Score & $40(34,45)$ & $40(33,45)$ & 0.847 \\
\hline - Patients with high anxiety & $73(17.6 \%)$ & $61(14.9 \%)$ & 0.284 \\
\hline After surgery & & & \\
\hline - Score & $37(32,41)$ & $37(32,42)$ & 0.953 \\
\hline - Patients with high anxiety & $53(12.8 \%)$ & $48(11.7 \%)$ & 0.632 \\
\hline STAIT & & & \\
\hline Before information & & & \\
\hline - Score & $38(34,43)$ & $38(34,43)$ & 0.922 \\
\hline - Patients with high anxiety & $108(26.1 \%)$ & $115(28.0 \%)$ & 0.526 \\
\hline After information & & & \\
\hline - Score & $38(33.75,43)$ & $37(33,42)$ & 0.349 \\
\hline - Patients with high anxiety & $97(23.4 \%)$ & $98(23.9 \%)$ & 0.873 \\
\hline After surgery & & & \\
\hline - Score & $36(32,40)$ & $36(33,41)$ & 0.969 \\
\hline - Patients with high anxiety & $71(17.1 \%)$ & $58(14.1 \%)$ & 0.236 \\
\hline Patients refused surgery & & & \\
\hline Number/total (\%) & $2 / 403(0.5 \%)$ & $4 / 404(1 \%)$ & 0.435 \\
\hline Patients refused regional anesthe & & & \\
\hline Number/total (\%) & $0(0 \%)$ & $0(0 \%)$ & \\
\hline Patients refused anesthetic inform & & & \\
\hline Number/total (\%) & $41 / 362(11.3 \%)$ & $88 / 403(21.8 \%)$ & $<0.001$ \\
\hline
\end{tabular}

Mann-Whitney U test for comparison of non-normally distributed data. Chi-square (or Fisher exact) test for comparison of qualitative data. 
Table 3. Visual analogue score (VAS) of knowledge perception in patients who received routine anesthetic information (control group) and detailed anesthetic-risk information (study group). Values are expressed as median (IQR).

\begin{tabular}{|c|c|c|c|}
\hline VAS of knowledge & $\begin{array}{c}\text { Control group } \\
(n=414)\end{array}$ & $\begin{array}{c}\text { Study group } \\
(\mathbf{n}=\mathbf{4 1 0})\end{array}$ & P-value \\
\hline \multicolumn{4}{|l|}{ Sore throat } \\
\hline Before information & $0(0,3)$ & $0(0,4)$ & 0.521 \\
\hline After information & $5(0,6)$ & $5(5,10)$ & $<0.001 *$ \\
\hline After surgery & $6(5,10)$ & $8(5,10)$ & $<0.001 *$ \\
\hline \multicolumn{4}{|l|}{ Nausea, vomiting } \\
\hline Before information & $0(0,5)$ & $0(0,5)$ & 0.939 \\
\hline After information & $0(0,7)$ & $5(5,10)$ & $<0.001 *$ \\
\hline After surgery & $6(5,10)$ & $8(5,10)$ & $<0.001 *$ \\
\hline \multicolumn{4}{|l|}{ Dental damage } \\
\hline Before information & $0(0,0)$ & $0(0,0)$ & 0.549 \\
\hline After information & $2(0,5)$ & $5(3,10)$ & $<0.001 *$ \\
\hline After surgery & $5(0,7)$ & $5(4,10)$ & $<0.001^{*}$ \\
\hline \multicolumn{4}{|c|}{ Not waking up after surgery } \\
\hline Before information & $0(0,1)$ & $0(0,2)$ & 0.197 \\
\hline After information & $2(0,5)$ & $5(2.75,9)$ & $<0.001 *$ \\
\hline After surgery & $5(0,6)$ & $5(4,9)$ & $<0.001 *$ \\
\hline \multicolumn{4}{|l|}{ Cardiac arrest } \\
\hline Before information & $0(0,0)$ & $0(0,2)$ & 0.055 \\
\hline After information & $0(0,5)$ & $5(2,8.5)$ & $<0.001 *$ \\
\hline After surgery & $4(0,6)$ & $5(3,9)$ & $<0.001 *$ \\
\hline
\end{tabular}

Mann Whitney U test was used for comparison of non parametric data. *statistically significant $(\mathrm{p}<0.05)$ compared with Control group.

Table 4. Factors affecting high state anxiety (STAIS) $>45$ after information by univariate analysis. Values are expressed as number (proportion).

\begin{tabular}{|c|c|c|c|}
\hline Factors & $\begin{array}{c}\text { Case with STAIS > 45, } \\
\text { number }(\%)\end{array}$ & $\begin{array}{l}\text { Crude odd ratio } \\
\text { (95\%CI) }\end{array}$ & P-value \\
\hline \multicolumn{4}{|c|}{ Hospital location ( $n=824)$} \\
\hline Rural & $94(22.2 \%)$ & 1 & 0.317 \\
\hline Urban & $101(25.2 \%)$ & $1.18(0.85,1.63)$ & \\
\hline \multicolumn{4}{|c|}{ University hospital ( $n=824)$} \\
\hline Non-university & 119(19.4\%) & 1 & $<0.001^{*}$ \\
\hline University & $76(35.8 \%)$ & $2.31(1.63,3.27)$ & \\
\hline \multicolumn{4}{|c|}{ Patients' habitat (n=799) } \\
\hline Rural & $135(22.5 \%)$ & 1 & 0.079 \\
\hline Urban & $57(28.6 \%)$ & $1.38(0.96,1.98)$ & \\
\hline \multicolumn{4}{|c|}{ Preoperative information $(n=824)$} \\
\hline No & $97(23.4 \%)$ & 1 & 0.873 \\
\hline Yes & $98(23.9 \%)$ & $1.03(0.74,1.42)$ & \\
\hline \multicolumn{4}{|l|}{$\operatorname{Sex}(n=824)$} \\
\hline Male & $72(20.5 \%)$ & 1 & 0.061 \\
\hline Female & $123(26.1 \%)$ & $1.37(0.99,1.91)$ & \\
\hline \multicolumn{4}{|l|}{ Age $(n=824)$} \\
\hline$>50$ years & $80(19.4 \%)$ & 1 & $0.004 *$ \\
\hline$\leq 50$ years & $115(28.0 \%)$ & $1.62(1.17,2.24)$ & \\
\hline
\end{tabular}


Table 4. Factors affecting high state anxiety (STAIS) > 45 after information by univariate analysis. Values are expressed as number (proportion). (Continued)

\begin{tabular}{|c|c|c|c|}
\hline Factors & $\begin{array}{l}\text { Case with STAIS > 45, } \\
\text { number }(\%)\end{array}$ & $\begin{array}{l}\text { Crude odd ratio } \\
\text { (95\% CI) }\end{array}$ & P-value \\
\hline \multicolumn{4}{|l|}{ STAIT baseline $(n=824)$} \\
\hline$<45$ & $94(13.7 \%)$ & 1 & \multirow[t]{2}{*}{$<0.001^{*}$} \\
\hline$>45$ & $101(74.3 \%)$ & 18.24(11.72, 28.36) & \\
\hline \multicolumn{4}{|l|}{ ASA physical status $(n=822)$} \\
\hline I-II & $184(23.7 \%)$ & 1 & \multirow[t]{2}{*}{0.907} \\
\hline III-V & $11(24.4 \%)$ & $1.04(0.52,2.10)$ & \\
\hline \multicolumn{4}{|l|}{ Experience $(n=821)$} \\
\hline Yes & $99(24.4 \%)$ & 1 & \multirow[t]{2}{*}{0.673} \\
\hline No & $96(23.1 \%)$ & $0.93(0.68,1.29)$ & \\
\hline \multicolumn{4}{|l|}{ Operative risk (n=824) } \\
\hline Moderate & $115(21.9 \%)$ & 1 & \multirow[t]{2}{*}{0.115} \\
\hline Low & $80(26.8 \%)$ & $1.30(0.94,1.81)$ & \\
\hline \multicolumn{4}{|l|}{ Anesthetic technique $(n=824)$} \\
\hline General anesthesia & $183(23.0 \%)$ & 1 & \multirow[t]{2}{*}{$0.032 *$} \\
\hline General+Regional anesthesia & $12(40.0 \%)$ & $2.26(1.05,4.71)$ & \\
\hline \multicolumn{4}{|l|}{ Education (n=823) } \\
\hline >High school & $33(21.3 \%)$ & 1 & \multirow[t]{2}{*}{0.435} \\
\hline$<$ High school & $162(24.3 \%)$ & $1.18(0.78,1.81)$ & \\
\hline \multicolumn{4}{|l|}{ Income/month $(n=751)$} \\
\hline$>10,000$ baht & $36(14.8 \%)$ & 1 & \multirow[t]{2}{*}{$<0.001^{*}$} \\
\hline$\leq 10,000$ baht & $137(27.2 \%)$ & $2.14(1.43,3.21)$ & \\
\hline
\end{tabular}

Table 5. Factors affecting high state anxiety (STAIS) $>45$, after information, by multiple logistic regression analysis.

\begin{tabular}{lll}
\hline Risk factors & $\begin{array}{c}\text { Adjusted odd ratio } \\
(\mathbf{9 5 \%} \text { CI) }\end{array}$ & P-value \\
\hline University hospital & $1.90(0.92,3.92)$ & 0.081 \\
Combined anesthesia & $1.54(0.94,2.54)$ & 0.090 \\
Low income of $<10,000$ baht/month & $2.57(1.42,4.65)$ & $0.002^{*}$ \\
High baseline Trait anxiety & $19.13(11.16,31.25)$ & $<0.001^{*}$ \\
\hline
\end{tabular}

*statistically significant ( $<$ 0.05), compared with the other group in each item from Table 4.

\section{Discussion}

This study demonstrated that detailed anestheticrisk information did increase patients' perception of five adverse events, by self assessment, but did not increase state-anxiety after receiving information. Based on stratified randomization, characteristics of patients, anesthetics and operative risk between groups were similar. Patients in university hospitals, the younger age group up to 50 years, higher baseline trait anxiety, combined anesthetic techniques and lower income were associated with high anxiety. After controlling for confounding factors, high baseline trait anxiety and lower income were the most important risk factors.

Our results concerning anxiety and knowledge were similar to the effect of pre-operative anesthesia risk information by Inglis and Farnill [7], and the effect of detailed, video-assisted anesthesia risk education 
by Salzwedel et al. [16]. Lee et al. [17] compared the effectiveness of media-based patient education about anesthesia, printed information without intervention. Subjects who received the video and printed information had less intense anxiety level before anesthesia than those receiving no intervention. Level of knowledge was higher in video group compared with patients with no intervention whereas the level of patient satisfaction was similar between groups.

According to our results from 824 patients, the prevalence of high-state anxiety was $23.7 \%$. The mean scores for state-anxiety and trait-anxiety were $40.88 \pm 8.39$ and $39.04 \pm 7.26$, respectively. These findings were comparable to the results by Caumo et al. [12]. They studied in 526 patients and found that the prevalence of high-state anxiety was $24.0 \%$. The mean scores for state-anxiety and trait-anxiety were $39.50 \pm 9.26$ and $39.28 \pm 10.19$ respectively. Risk factors from their study included history of cancer and smoking, psychiatric disorders, negative future perceptions, moderate to intense depressive symptoms, high trait-anxiety, moderate-to-intense pain, medium level surgery, female gender, ASA category III, up to 12 years of education, and more than 12 years of education. Previous surgery reduced the risk of preoperative anxiety.

The reason for low median state anxiety score after receiving anesthetic-risk information might be related to the clear and comprehensive written descriptive format of incidents, including a community cluster logarithmic scale of risk. This scale clearly identified that the serious adverse events rarely occurred, compared with the rare events in daily life. Another reason might be attributed to the predominantly low overall operative risk in this study which might not induce high anxiety. Moreover, trust and good doctor-patient relationships might also lower anxiety level of the patients in spite of detailed risk information.

Uzbeck et al. [18] compared the effect of simple or more detailed written information about the risks of bronchoscopy on peri-procedure anxiety and satisfaction of 142 consecutive patients. They found that those who received more detailed risk information had significantly greater increase in anxiety levels (visual analogue scale and modified Amsterdam preoperative anxiety) than those who received simple information. Almost twice as many of those receiving detailed risk information reported they felt they received too much information about complications or that the information they had received about bronchoscopy had been worrying. The contradictory results of increasing anxiety in that study might be related to excess information in a limited period of time before procedure. The Association of Anaesthetists of Great Britain and Ireland recommend that: "patients must be given sufficient time to form a considered view after they have been provided with relevant information. It is neither desirable nor practical for all information to be provided to patients at the pre-operative visit, and unacceptable for new information to be provided in the anesthetic room. Detailed information should not be forced upon patients who have indicated clearly that they do not want to hear it, but written information should be left in case they decide later they would like to know it [6]. Therefore, simple and clear information in the appropriate time-period might be the state-of-art for provision.

In our study, the most important factors to increase state anxiety from anesthetic-risk information were high trait anxiety level, which might be confounded with the other independent risk factors such as assessing patients in a university hospital, age up to 50 years, combined anesthetic technique and lower income. Patients at Pichit Hospital, Budhachinaraj Hospital, and Prasart Neurological Institute came predominantly from rural area where the ways of life were still simple and relaxed in a helpful environment. These might cause a lower traitanxiety level and a lower state-anxiety level than patients in university hospitals.

This study had some limitations. First, patients in our study were all public patients. They did not have the high expectations as private patients. They still felt trust towards the doctors. Even anestheticrisk information did not make any difference more than general preoperative anxiety. Second, most of operations in this study were low risk. This might not induce high anxiety. Therefore, the results of this study might not be valid if extrapolated to severe risk surgery and private patients with high expectations.

In conclusion, provision of printed anesthetic-risk information did not increase anxiety but increased knowledge perception of adverse events. The most important risk factors were high trait-anxiety and low income. 


\section{Acknowledgement}

The authors wish to thank Dr. Chulaluk Komoltri for her statistical advice. We also thank the Royal College of Anesthesiologists of Thailand and Siriraj Research Development Fund for financial support. The authors have no conflict of interest to report.

\section{References}

1. National Health and Medical Research Council. General guidelines for medical practitioners on providing information to patients. Canberra:Australian Government Publishing Service, 1993.

2. General Medical Council. Seeking patients consent: the Ethical Considerations. London:General Medical Council, 1999.

3. Litman RS, Perkins FM, Dawson SC. Parental knowledge and attitudes toward discussing the risk of death from anesthesia. Anesth Analg. 1993; 77:256-60.

4. Lonsdale M, Hutchison GL. Patients' desire for information about anesthesia: Scottish and Canadian attitudes. Anesthesia. 1991; 46:410-2.

5. Aitkenhead AR. Informing and consenting for anaesthesia. Best Pract Res Clin Anaesthesiol. 2006; 20:507-24.

6. Consent for Anesthesia. Association of Anesthetists of Great Britain and Ireland, London: 2006.

7. Inglis S, Farnill D. The effects of providing preoperative statistical anaesthetic-risk information. Anaesthesia Intensive Care. 1993; 21:799-805.

8. Charuluxananan S, Punjasawadwong Y, Suraseranivongse S, Srisawasdi S, Kyokong O, Chinachoti T, et al. The Thai Anesthesia Incidents Study (THAI Study) of anesthetic outcomes: II Anesthetic profiles and adverse events. J Med Assoc Thai. 2005; 88(Suppl 7): S14-29.

9. Jenkins K, Baker AB. Consent and anaesthetic risk. Anaesthesia. 2003; 58:962-84.
10. Calman KC, Royston HD. Risk language and dialects. BMJ. 1997; 315:934-42.

11. Adams AM, Smith AF. Risk perception and communication: recent developments and implication for aneaesthesia. Anaesthesia. 2001; 56:745-55.

12. Caumo W, Schmidt AP, Schneider CN, Bergmann J, Iwamoto CW, Bandeira D, et al. Risk factors for preoperative anxiety in adults. Acta Anaesth Scand. 2001; 45:298-307.

13. Fleisher LA, Beckman JA, Brown KA, Calkins H, Chaikoff E, Flishmann KE, et al. ACC/AHA Guidelines on perioperative cardiovascular evaluation and care for non cardiac surgery. J Am Coll Cardiol. 2007; 50: e159-241. Available from doi: 10.1016/j.jacc.2077.09.003.

14. Spielberger CD, Gorush RL, Lushene RE, Vagg PR, Jacobs GA. Manual for the State-Trait Anxiety Inventory. Palo Alto: Consulting Psychologists Press, 1983.

15. Klinder $\mathrm{CH}$, Harms C, Amsler F, Ihde-Scholl T, Scheidegger $\mathrm{D}$. The visual analog scale allows effective measurement of preoperative anxiety and detection of patients' anesthetic concerns. Anesth Analg. 2000; 90: 706-12.

16. Salzwedel C, Petersen C, Blanc I, Koch U, Goetz AE, Schuster M. The effect of detailed, video-assisted anesthesia risk education on patient anxiety and the duration of the preanesthetic interview: a randomized controlled trial. Anesth Analg. 2008; 106:202-9.

17. Lee A, Chui T, Gin T. Educating patients about anesthesia: a systematic review of randomized controlled trials of media-based interventions. Anesth Analg. 2003; 96: 1423-31.

18. Uzbeck M, Quinn C, Saleem I, Cotter P, Gilmartin JJ, O’Keeffe ST. Randomized controlled trial of the effect of standard and detailed risk disclosure prior to bronchoscopy on peri-procedure anxiety and satisfaction. Thorax. 2009; 64:224-7. 